\title{
No seasonal variation in physical activity of Han Chinese living in Beijing
}

\author{
Guanlin Wang ${ }^{1,2}$, Baoguo Li ${ }^{1,2}$, Xueying Zhang ${ }^{1,2}$, Chaoqun Niu', Jianbo Li ${ }^{1,3}, \mathrm{Li} \mathrm{Li}^{1,2}$ and John R. Speakman ${ }^{1,4^{*}}$
}

\begin{abstract}
Background: Physical activity (PA) is widely acknowledged to be beneficial to health and wellbeing, and is potentially influenced by a variety of environmental factors such as ambient temperature, weather conditions and air pollution levels. Since these factors vary seasonally, physical activity participation may also respond seasonally. Current population studies to profile physical activity often sample individuals only once, and this may result in biased estimates if there is strong seasonal variation.

Methods: We conducted a study of 40 Han Chinese adults living in Beijing using GT3X accelerometers. We measured PA levels every two months across a complete year, while simultaneously monitoring ambient temperatures and air pollution levels. Average hourly vector magnitude (VM) and percentage time spent at each PA intensity (sedentary to light, moderate, vigorous and very vigorous) were measured. General Linear models (GLMs) were used to explore the effects of time of day, temperature and PM 2.5 levels on PA. One way ANOVA was used to test whether there were seasonal differences in body weight and body fatness.

Results: The main factors influencing activity levels were the time of day and individual characteristics including age and body fatness, but there was no significant difference between the months. In addition, there was no significant impact of either ambient temperature or air pollution levels (PM2.5). There were also no significant differences over the year in the time spent at sedentary-light, moderate and very vigorous PA levels, but for vigorous PA level which occupied less than $0.5 \%$ daily physical activity, both month and individual were significant factors.

Conclusions: The relatively constant pattern of urban daily life, independent of time of year, may override the potential impacts of environmental factors that would be anticipated to impact PA levels. These subjects did not specifically avoid activity coincident with elevated air pollution levels (PM2.5). Single week long measurements of physical activity could provide a representative measurement of the physical active levels in this population.
\end{abstract}

Keywords: Physical activity, Obesity, Environment, Seasonal variation, Han Chinese, Temperature, PM2.5, Intensity

\section{Background}

Physical inactivity has become a leading risk of noncommunicable diseases including cardiovascular disease, type 2 diabetes mellitus (T2D) and cancer [1,2]. Participation in at least 150 min per week of moderate to vigorous physical activity (MVPA) has been reported to decrease blood pressure, alleviate type 2 diabetes (T2D) and reduce the risk of cancer $[1,3-5]$, and was therefore

\footnotetext{
* Correspondence: j.speakman@abdn.ac.uk

${ }^{1}$ State Key Laboratory of Molecular Developmental Biology, Institute of Genetics and Developmental Biology, Chinese Academy of Sciences, Beijing, China

${ }^{4}$ Institute of Biological and Environmental Sciences, University of Aberdeen, Aberdeen, UK

Full list of author information is available at the end of the article
}

recommended by the WHO as a target level of physical activity for adults aged 18-64 [1]. However, it was estimated that globally around $23 \%$ of adults $(20 \%$ of males and $27 \%$ of females) aged 18 and over did not meet these guideline levels in 2010 [1].

Although several studies have suggested that there is a genetic contribution to the differences of PA levels [6-9], it is generally assumed that participation in PA is mostly under voluntary control, and it is believed that environmental conditions exert either a facilitating or constraining influence on such voluntary participation [10]. Such factors include variation in ambient temperature, because individuals may avoid exercise when it is too hot because of the risk of hyperthermia [11] and when it is subzero 
because of the possible risk of falls and injury during activity, due to ice formation. Other weather conditions, such as strong wind, precipitation and/or other extreme weathers may also influence activity levels [10]. The duration of daytime may also be an important factor for both convenience and safety considerations of being outside during the period of darkness [10]. All of these factors vary seasonally and to different extents in different places, hence it is expected that PA levels may also vary temporally and spatially. This may then have a large impact on the spatial and temporal patterns of disease risk $[12,13]$. In the USA, for example the prevalence of type 2 diabetes is increased in areas with higher average annual temperatures [12], which could in theory be contributed to by people avoiding activity at higher temperatures. It has been previously demonstrated that seasonal PA changes coincided with seasonal changes in blood pressure, body mass and affective disorders $[14,15]$.

Air quality, especially PM 2.5 (the levels of particulate matter with a diameter less than 2.5 microns), is a major public health issue in many large cities [16-18]. High levels of PM2.5 have been shown to be detrimental to health, causing respiratory disorders and severe lung dysfunction, along with elevated risks of lung cancer and cardiovascular events $[19,20]$. It seems likely that the health benefits of PA may be negated at high levels of air pollution [18]. However, the extent to which urban individuals avoid being active when PM2.5 levels are high is currently unknown. PM2.5 also varies seasonally [21], leading to an additional potential seasonal impact on both PA and health [22].

Several different approaches are available for quantification of PA levels, from subjective measurements like self-report questionnaires [23-25], to various forms of direct assessment, including doubly-labeled water [26], pedometers [27], heart rate monitors (HRMs) [28] and accelerometers [29]. Tri-axial accelerometers are small monitors that record movements of the body in three dimensions and have hence emerged as a popular method for objectively monitoring PA levels [30]. Among such accelerometers, the GT3X (ActiGraph, Inc. Pensacola FL, USA) is a particularly popular device to explore objective patterns of PA in terms of the elemental characteristics such as intensity, duration and frequency [31]. The GT3X has been used in a large number of studies including the National Health Assessment in the USA (NHANES) [32].

Almost all population based studies of PA have used single measurements, averaged over a few adjacent days, to profile the PA levels. It is unclear whether single measurements provide an adequate representation of PA. For example, there could be large biases if there were large seasonal differences in PA. This is especially the case for meta-analyses or comparison studies where the differences due to seasonal effects may override other effects, or generate spurious differences between populations.

Previous studies of adults in the UK [33-36], US [14, 37] Netherlands [38] and Canada [39] all showed seasonal variation in physical activity, with higher PA levels observed in summer compared with winter, using both self-report assessments or pedometers or doubly-labled water and accelerometers to record PA. Similar results were also shown in studies on seasonal variations in children (aged 8-11) in Denmark [40]. A review by Rich [41] also reported that overall PA of children living in UK is lower during winter. In Norway, 9-years-old children had significantly higher mean physical activity levels in spring than in winter and fall, when measured using a uni-axial MTI Actigraph accelerometer (Model: 7164), however, no associations were found between mean physical activity level and season among 15-year-olds in Norway [42]. Contrasting these studies showing higher activity in summer, a study using GT3X monitoring of the PA of Australian children suggested that PA decreased in summer compared to winter [43]. These differences potentially reflect the prevailing ambient temperature regime in the respective locations-in Melbourne, Australia at $37^{\circ} \mathrm{S}$ it may be too hot to exercise in summer, while in Norway at $57-72{ }^{\circ} \mathrm{N}$ it may be too cold to exercise in winter. To our knowledge, no published studies of seasonal variation in PA have been performed in Han Chinese populations.

Beijing, the capital city of China, at $40{ }^{\circ} \mathrm{N}$ is profoundly seasonal in its climate, with hot summers that have ambient temperatures routinely over $40{ }^{\circ} \mathrm{C}$ and cold winters, with ambient temperatures often falling to $-10{ }^{\circ} \mathrm{C}$. Most precipitation falls in the summer. In addition, it has high and extremely variable levels of air pollution (PM2.5) which can vary from an air quality index (AQI) of 10 to over 600. In the present study we recruited 40 Han Chinese adults living in Beijing (defined as living inside the $6^{\text {th }}$ ring road) to examine (1) whether there was a seasonal effect on the average hourly PA measured over 7 continuous days; (2) whether the ambient temperature and PM2.5 influenced the intensity and duration of the PA; (3) whether there was an overall seasonal effect on different intensities of activity.

\section{Methods}

Subjects

Forty volunteers (19 females and 21 males) were recruited by posters near Olympic Park in Chaoyang District, Beijing. Of the 40 volunteers, 18 were Master/ Ph.D students of University of Chinese Academy of Sciences located next to the park, the rest had various occupations, but all were in employment. At the end of 1 year, 37 individuals had completed the study (3 women dropped out due to pregnancy). Data from 34 individuals 
(13 female and 21 male, aged $31 \pm 10$ ) were used for final analysis (provided valid data for at least 4 days in each measurement period, study flowchart, Additional file 1: Figure S1). The subjects were asked to visit our lab every 2 months to get a GT3X device fitted and had their body composition measured using TANITA • TBF-418B. During their first visit they additionally had their height, weight, waist and hip circumference, body composition, blood pressure, heart rate measured and they completed a life-style questionnaire (see in Additional file 1). Subject characteristics are in Table 1.

\section{Physical activity measurements}

The subjects were instructed to wear a GT3X monitor on a waist band for $24 \mathrm{~h}$ a day (including sleeping time) over 7 continuous days and to remove the monitor only during showers, bathing, swimming or other water activities. Activity loggers were fitted to each individual every 2 months, i.e., in January, March, May, July, September and November in 2015 respectively (see in Additional file 1). The recording epoch was set to record by minute. Hourly physical activity was summed using the minutes' VM (vector magnitude) data within an hour (here we defined as from 0:00 to 0:59 as $1 \mathrm{~h}$ ). Then we calculated average hourly PA across days when the monitor was worn called 'worn days' (at least 4 worn days was regarded as a valid sample) of each subject in each month. Percentage time spent in different physical activity (PA) intensity levels (sedentary to light, moderate, vigorous and very vigorous) of the worn time was used to examine the difference of seasonal variability.

\section{Temperature and PM 2.5 data Acquisition}

Hourly temperature and PM 2.5 data was obtained from the Beijing Urban Ecosystem Research Station. The data collection site is at $40.00729{ }^{\circ} \mathrm{N}, 116.3374{ }^{\circ} \mathrm{E}$. This is around $6 \mathrm{~km}$ from the general area where the subjects were recruited. The data paired with physical activity period was selected for analysis.

\section{Statistics}

Minitab 16 was used to analyze the data. We used oneway ANOVA to compare whether there was a change in body composition between months. General linear models (GLM) were used to analyze the temperature differences between months and the Tukey method (95\% confidence) was used for pairwise comparison by month. Month, time and month"time were set as factors. We also used GLM to examine the PM2.5 difference using month, time and month"time as factors with temperature as a covariate. Tukey tests (95\% confidence) were used for pairwise comparison by month. Mixed models were used to analyze the difference in average hourly PA levels (mean hourly VM), we used month (the seasonal factor, fixed), time of day (fixed), ID (random), month"time, month"ID and time*ID as factors, with simultaneous hourly ambient temperature data $\left({ }^{\circ} \mathrm{C}\right)$ and air quality data (PM 2.5) as covariates. None of the interactions were significant and were eliminated. For physical activity intensity comparison, we used percentage of total physical activity as response and included month and ID as factors and temperature and PM2.5 as covariates. Further individual characteristics analysis were used GLM including month as factor which covaried with age and body fatness (body fat percentage).

\section{Results}

Temperature and air quality (PM2.5) varied seasonally Hourly temperature $\left({ }^{\circ} \mathrm{C}\right)$ and air quality (PM2.5) data for the days when subjects were wearing activity loggers were retrieved and compared by month. There were clear seasonal variations of both temperature and

Table 1 Baseline of demographic and anthropometric variables in 34 subjects (involved in final data processing

\begin{tabular}{lccc}
\hline & Total (Mean \pm SD) & Female (Mean \pm SD) & Male (Mean \pm SD) \\
\hline Age (years) & $31 \pm 10$ & $33 \pm 12$ & $29 \pm 8$ \\
Weight $(\mathrm{kg})$ & $66.3 \pm 8.6$ & $61.1 \pm 6.7$ & $69.5 \pm 8.2$ \\
BMI (kg/m2) & $23.1 \pm 2.3$ & $23.0 \pm 2.2$ & $23.2 \pm 2.4$ \\
$\%$ BF & $23.2 \pm 7.7$ & $31.3 \pm 3.8$ & $18.3 \pm 4.5$ \\
FM (kg) & $15.4 \pm 5.5$ & $19.3 \pm 4.4$ & $12.9 \pm 4.6$ \\
FFM (kg) & $50.9 \pm 8.4$ & $41.8 \pm 2.8$ & $56.6 \pm 4.8$ \\
WC (cm) & $83.1 \pm 7.7$ & $78.8 \pm 6.0$ & $85.7 \pm 7.5$ \\
HC (cm) & $99.5 \pm 4.4$ & $100.0 \pm 4.4$ & $99.1 \pm 4.5$ \\
SBP & $124 \pm 16$ & $115 \pm 18$ & $129 \pm 12$ \\
DBP & $75 \pm 11$ & $73 \pm 13$ & $77 \pm 9$ \\
HR & $74 \pm 9$ & $71 \pm 7$ & $76 \pm 10$ \\
\hline
\end{tabular}

$B M I$ body mass index, $\% B F$ body fat percentage, $F M$ fat mass, FFM fat free mass, WC waist circumference, $H C$ hip circumference, $S B P$ systolic blood pressure, $D B P$ diastolic blood pressure, $H R$ heart rate 
PM2.5. Month, time of day and the interaction between month and time of day all had significant effects on the ambient temperature (Fig. 1a, $\mathrm{F}_{(5,4512)}$ month $=36377.29$, $P<0.001 ; \mathrm{F}_{(23,4512)}$ time of day $=550.81, P<0.001 ; \mathrm{F}_{(115}$, 4512) month"time of day $=15.85, P<0.001)$. In July, the average temperature was $29.3{ }^{\circ} \mathrm{C}$ while in January it was $1.6{ }^{\circ} \mathrm{C}$. PM 2.5 level also varied by different seasons. Month, time of day and month*time of day as well as ambient temperature were all significant factors influencing the PM2.5 levels (Fig. 1b, $\mathrm{F}_{(5,4511)}$ month $=544.09$, $P<0.001 ; \mathrm{F}_{(23,4512)}$ time of day $=141.12, P<0.001 ; \mathrm{F}_{(115,}$ 4511) month"time of day $=38.43, P<0.001, \mathrm{~F}_{(1,4512)}$ temperature $=603.95, P<0.001)$. In May, the average PM 2.5 was 47 , which was significantly lower than in January when it averaged 81 and November when it was on average 80 .

\section{No seasonal body composition change}

Subjects were measured for basic demographic and anthropometric data before the first measurement period (Table 1). Body composition was measured on each occasion that the GT3X was worn. Over the following year there was no significant effect of month on body weight (kg) (Fig. 2, one-way ANOVA: $\mathrm{F}_{(5,190)}=0.06, P=0.998$ ), body fat percentage (\%BF) (Fig. 2, one-way ANOVA: $\mathrm{F}_{(5,190)}$ $=0.3, P=0.912$ ), fat mass (FM, kg) (Fig. 2, one way ANOVA: $\left.\mathrm{F}_{(5,190)}=0.32, P=0.900\right)$ and fat free mass (FFM, kg) (Fig. 2, one way ANOVA: $\mathrm{F}_{(5,190)}=0.08, P=0.995$ ).

\section{No seasonal effect on average hourly PA}

We calculated the average hourly vector magnitude (VM) for each hour over the whole 7 day period of measurement of each subject every 2 months (Table 2). The patterns of average hourly physical activity measurement are illustrated in Fig. 3. In Fig. 3a, the darker blue indicates higher physical activity. Periods of high PA occurred at around 9:00, 13:00 and 18:00-19:00. The highest VM level was around 50,000 counts/h (Fig. 3b). We found both individual ID $\left(\mathrm{F}_{(33,4567)}=16.05, P<0.001\right)$ and time of day $\left(\mathrm{F}_{(23,4567)}=105.37, P<0.001\right)$ were significantly associated with $\mathrm{PA}$, however, month was not a significant factor $\left(\mathrm{F}_{(5,4567)}=0.64, P=0.668\right)$. Although there were significant seasonal differences in both ambient temperature and PM2.5 (Fig. 1), neither temperature $\left(\mathrm{F}_{(1,4567)}=2.54, P=0.111\right)$ nor PM2.5 $\left(\mathrm{F}_{(1,4567)}=0.04, P=\right.$ $0.836)$ had significant effects on the average hourly PA. The absence of an effect of these factors could be because each day included a significant portion of time when subjects were inactive because they were sleeping, and this day to nighttime difference dominated any other patterns of variation. To explore this possibility we analyzed the data collected between 9:00 and 23:00 to remove the sleeping time. The results were similar to those collected when the whole day was included in the analysis, with time of day and ID the most significant factors $\left(\mathrm{F}_{(5,2854)}\right.$ month $=1.28, P=0.268 ; \mathrm{F}_{(14,2854)}$ time $=$ 30.7, $\left.P<0.001 ; \mathrm{F}_{(33,2854) \text { ID }}=16.2, P<0.001\right)$ but no significant effects of temperature or PM2.5 $\left(\mathrm{F}_{(1,2854)}\right.$ temperature $\left.=3.18, P=0.074, \mathrm{~F}_{(1,2854)} \mathrm{PM} 2.5=0, P=0.986\right)$. As ID was an important indicator, we also calculated the average daily PA as a response variable, with month, age and average body fatness to establish the characteristics of individuals that influence their PA. Both fatness and
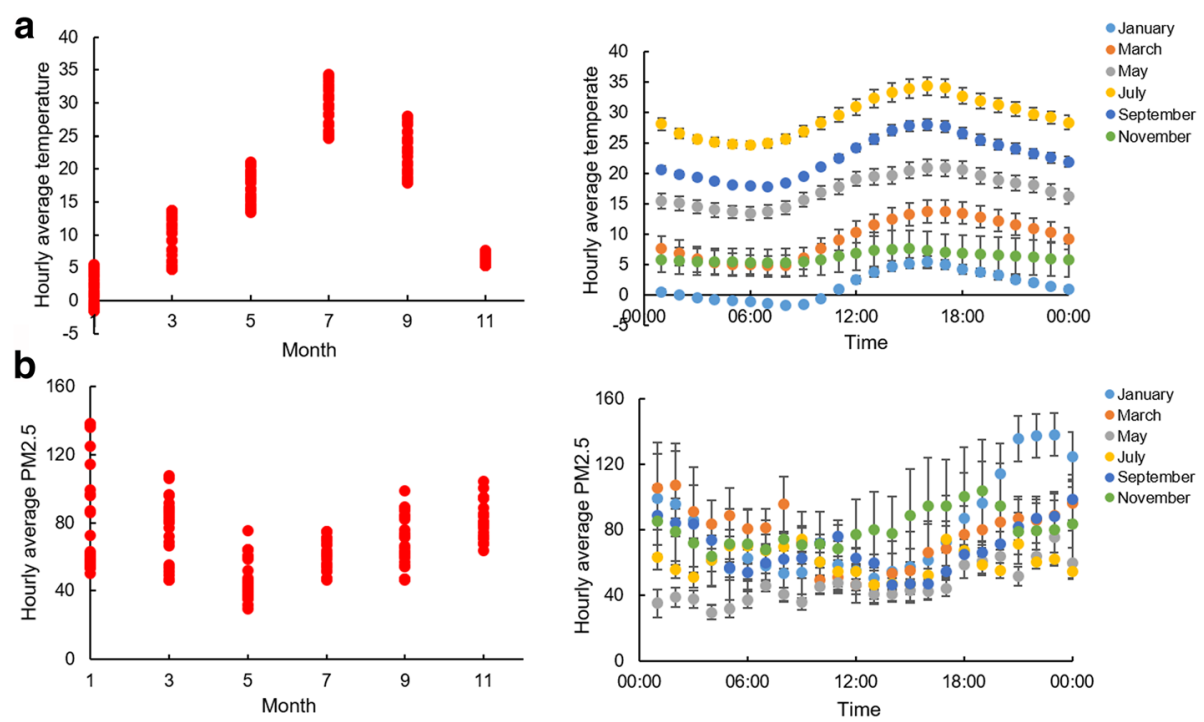

Fig. 1 Seasonal variation of temperature and PM2.5. a shows the monthly difference of temperature and hourly average temperature range from January, March, May, July, September and November across the complete year (2015). There was a significant difference of temperature monthly and hourly. $\mathbf{b}$ shows the monthly difference of PM2.5 and hourly average PM2.5 during the six measured months. There was a significant difference of PM2.5 monthly and hourly which also covaried with temperature 

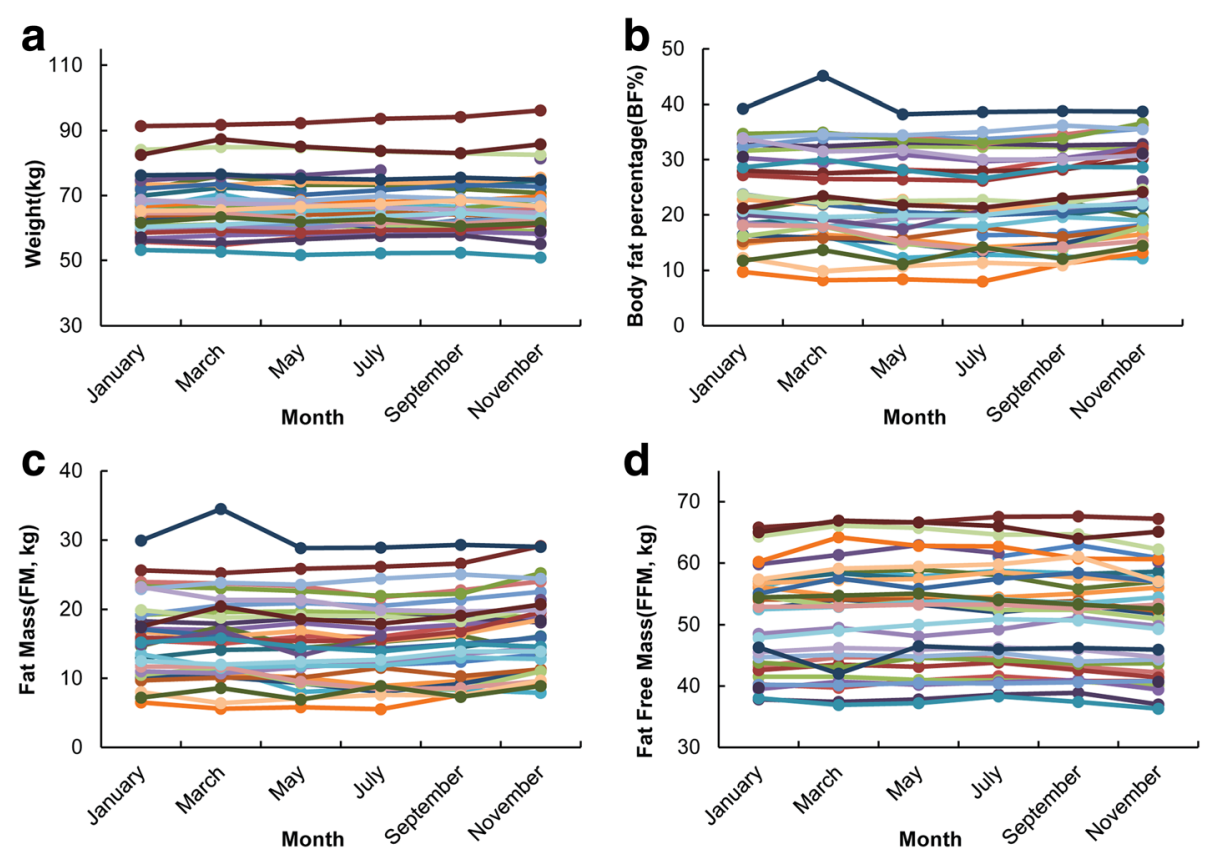

Fig. 2 Seasonal difference in body composition. a is the seasonal difference in body weight. Each point represents an individual. b represents the seasonal difference in body fat percentage. $\mathbf{c}$ shows the seasonal difference of fat mass. $\mathbf{d}$ shows the seasonal difference of fat free mass. There was no significant effect of season for any of the traits

age were significantly associated with the PA level $\left(\mathrm{F}_{(1,191) \text { age }}=5.74, \mathrm{P}=0.017, \mathrm{~F}_{(1,191) \text { body fatness }}=6.49, P=\right.$ $0.012)$. There was a negative relationship between body fatness and the PA level $(\mathrm{t}=-2.55, P=0.012)$ indicating that individuals with higher body fatness level were less active than those with lower body fatness. We also found that there was a positive relationship between age group and activity, indicating that older people were more active than younger ones in our volunteer group $(t=2.40$, $P=0.017)$.

\section{No seasonal effect on physical activity intensity}

We divided the PA into four intensity categories using the cut-points defined by Freedson Adult VM3 2011 [44] which included sedentary to light $(0 \sim 2689$ CPM), moderate $(2690 \sim 6166 \mathrm{CPM})$, vigorous (6167 9642 CPM) and very vigorous (>9643 CPM). We then quantified the percentage duration of PA at each activity level over the entire time each individual spent wearing the devices (Fig. 4a). Sedentary to light physical activity occupied around $95 \%$ of total time, the moderate to vigorous physical activity (MVPA), which included moderate, vigorous and very vigorous physical activity was less than $5 \%$ of the total time. Despite this MVPA was still on average around $504(60 * 24 * 7 * 0.05)$ minutes per week. Month, temperature and PM2.5 were not significant factors associated with sedentary to light, moderate and very vigorous PA levels, but again ID was significant (Sedentary to light: $\mathrm{F}_{(5,153) \text { month }}=1.05, \quad P=0.388$;
$\mathrm{F}_{(33,153) \text { ID }}=10.1, \quad P<0.001, \mathrm{~F}_{(1,153)}$ temperature $=0.53, \quad P=$ 0.469, $\quad \mathrm{F}_{(1,153) \mathrm{PM} 2.5}=0.31, \quad P=0.579 ; \quad$ Moderate: $\mathrm{F}_{(5,153) \text { month }}=0.79, P=0.555 ; \mathrm{F}_{(33,153) \mathrm{ID}}=6.72, P<0.001$, $\mathrm{F}_{(1,153) \text { temperature }}=0.69, P=0.407, \mathrm{~F}_{(1,153) \mathrm{PM} 2.5}=0.04, P=$ 0.837; Very Vigorous: $F_{(5,153) \text { month }}=1.22, \quad P=0.304$; $\mathrm{F}_{(33,153) \text { ID }}=1.91, \quad P=0.005, \quad \mathrm{~F}_{(1,153) \text { temperature }}=1.06, \quad P=$ $\left.0.305, \quad F_{(1,153) \text { PM2.5 }}=0.01, \quad P=0.907\right)$. However, both month and ID were significantly associated with levels of vigorous PA. Temperature and PM2.5 were again not significant (Vigorous: $F(5,153)$ month $=3.15, \quad P=0.01$; $\mathrm{F}_{(33,153) \mathrm{ID}}=10.1, \quad P<0.001, \mathrm{~F}_{(1,153)}$ temperature $=0, \quad P=$ $\left.0.995, F_{(1,153)} \mathrm{PM}_{2.5}=2.78, P=0.098\right)$. Although there was an association between time spent in vigorous physical activity and month, it only occupied less than $0.5 \%$ of the time and this effect was insufficient to change the total physical activity level (Fig. 4b).

\section{Discussion}

Physical inactivity has been identified as the fourth leading risk factor for global mortality causing an estimated 3.2 million deaths [1]. PA is thought to be largely under voluntary control and may therefore be highly responsive to various environmental factors - such as weather conditions, ambient temperature and air pollution levels. Since such factors vary spatially and temporally, the resultant variation in PA may contribute to the spatial and temporal variation in reported levels of noncommunicable diseases [12]. 
Table 2 Average hourly vector magnitude (VM) for each hour of every 2 months

\begin{tabular}{|c|c|c|c|c|c|c|c|c|c|c|c|c|}
\hline \multirow[t]{2}{*}{ Time } & \multicolumn{2}{|c|}{ January } & \multicolumn{2}{|l|}{ March } & \multicolumn{2}{|l|}{ May } & \multicolumn{2}{|l|}{ July } & \multicolumn{2}{|c|}{ September } & \multicolumn{2}{|c|}{ November } \\
\hline & mean & SD & mean & SD & mean & SD & mean & SD & mean & SD & mean & SD \\
\hline 01:00:00 & 7831 & 8336 & 9068 & 9862 & 8993 & 11871 & 10927 & 10702 & 10165 & 7006 & 11171 & 12113 \\
\hline 02:00:00 & 2802 & 3332 & 2823 & 2739 & 3427 & 3442 & 4799 & 4768 & 5503 & 9579 & 4558 & 4803 \\
\hline 03:00:00 & 2066 & 1647 & 1680 & 1490 & 2554 & 3635 & 1973 & 1418 & 2009 & 1855 & 2384 & 2229 \\
\hline 04:00:00 & 1420 & 749 & 1573 & 997 & 2700 & 3835 & 1953 & 1653 & 2159 & 2026 & 1557 & 1127 \\
\hline 05:00:00 & 1872 & 1452 & 1779 & 1167 & 2362 & 2470 & 2663 & 2568 & 2161 & 1949 & 1995 & 1215 \\
\hline 06:00:00 & 3586 & 6220 & 3777 & 9433 & 8211 & 22993 & 4931 & 9385 & 5029 & 7691 & 2912 & 3778 \\
\hline 07:00:00 & 9455 & 15188 & 9681 & 13423 & 12937 & 21180 & 11864 & 16728 & 12816 & 14096 & 9608 & 12958 \\
\hline 08:00:00 & 20873 & 18247 & 24149 & 18282 & 24675 & 20639 & 28698 & 24599 & 27964 & 24561 & 21916 & 24855 \\
\hline 09:00:00 & 42184 & 25712 & 39588 & 25187 & 38419 & 19582 & 39049 & 22611 & 35537 & 21203 & 39760 & 28426 \\
\hline 10:00:00 & 35910 & 20961 & 34122 & 18261 & 32597 & 12718 & 34102 & 11699 & 33315 & 12061 & 35692 & 13651 \\
\hline 11:00:00 & 31767 & 18405 & 27697 & 19375 & 30349 & 16666 & 31732 & 13350 & 30495 & 12069 & 29788 & 13300 \\
\hline 12:00:00 & 41435 & 16396 & 44139 & 16022 & 45558 & 19140 & 40854 & 18785 & 42674 & 14120 & 41905 & 16227 \\
\hline 13:00:00 & 43968 & 22009 & 46963 & 26146 & 44274 & 27049 & 44295 & 32324 & 50311 & 31082 & 52027 & 32190 \\
\hline 14:00:00 & 29995 & 14240 & 32829 & 20081 & 31548 & 12555 & 28650 & 16233 & 32528 & 12388 & 42024 & 16935 \\
\hline 15:00:00 & 29038 & 13949 & 33505 & 17543 & 27704 & 10697 & 28803 & 16407 & 31464 & 13853 & 33841 & 17615 \\
\hline 16:00:00 & 34924 & 26957 & 36603 & 21291 & 30419 & 11419 & 34266 & 15982 & 26559 & 11839 & 32181 & 14114 \\
\hline 17:00:00 & 40352 & 36797 & 39954 & 24163 & 38600 & 17657 & 31941 & 14782 & 30843 & 9660 & 33069 & 16182 \\
\hline 18:00:00 & 48932 & 26282 & 53389 & 26688 & 53635 & 20178 & 43934 & 20554 & 46715 & 20282 & 45489 & 17540 \\
\hline 19:00:00 & 51556 & 18264 & 56512 & 24806 & 49271 & 15903 & 49066 & 17664 & 54047 & 30909 & 42926 & 18382 \\
\hline 20:00:00 & 40837 & 19268 & 44352 & 27134 & 41169 & 21697 & 38385 & 17214 & 44948 & 27716 & 37415 & 20501 \\
\hline 21:00:00 & 35284 & 24434 & 31589 & 24902 & 35098 & 19656 & 33633 & 17563 & 37905 & 26054 & 30694 & 19646 \\
\hline 22:00:00 & 30293 & 18278 & 27841 & 24975 & 30998 & 23039 & 28539 & 17309 & 34276 & 25341 & 29346 & 15936 \\
\hline 23:00:00 & 25611 & 17222 & 22494 & 17917 & 27420 & 20864 & 30471 & 15741 & 27355 & 17910 & 24169 & 11991 \\
\hline 00:00:00 & 15854 & 10915 & 18433 & 15171 & 18353 & 14281 & 19825 & 10849 & 19885 & 16433 & 19503 & 13609 \\
\hline
\end{tabular}

Current studies on seasonal variation in PA have generated inconsistent results. Although most of the studies in European and North American populations [14, 33-37, 39-41] found that adults and children were generally more active in summer/spring and had lower PA levels in winter, using both self-reported measures and objective measurements. A study in Australia found that children were more active in winter rather than summer [43]. Studies in adolescents suggested that that there was no seasonal variation in physical activity [42].

To date no studies of seasonal variation have been performed in Han Chinese populations. In our study we found that there was no seasonal differences in the average hourly PA, despite the fact that there were large significant differences in ambient temperature and PM2.5 across the seasons and time of day. In summer in Beijing it was on average $25{ }^{\circ} \mathrm{C}$ hotter than in winter, during these measurements, while the air-quality was much worse in winter than in the other seasons [21]. A potential explanation for the absence of a seasonal effect on PA is that the weeks we measured were all working weeks, and the subjects we measured, who were all in employment, adopted a daily activity pattern that was largely dominated by the demands of their work and unresponsive to external stimuli. This finding was consistent with several previous publications $[45,46]$ that found sedentary to light physical activity occupied almost all of the total physical activity (using Freedson VM2011). In our study, the sedentary to light physical activity occupied over $95 \%$ of the time and there was no seasonal difference of sedentary to light, moderate and very vigorous physical activity. Although we found a seasonal effect on vigorous physical activity, it occupied less than $0.5 \%$ of the time. Such high levels of sedentariness may explain why there was no seasonal difference of overall physical activity. MVPA is regarded as a factor that influences the health status and a suggested 150 min per week would provide benefits to health outcomes. In our work, the MVPA level was almost $5 \%$ of total physical activity which is equivalent to $500 \mathrm{~min}$ per week. This indicates that all these subjects met the 


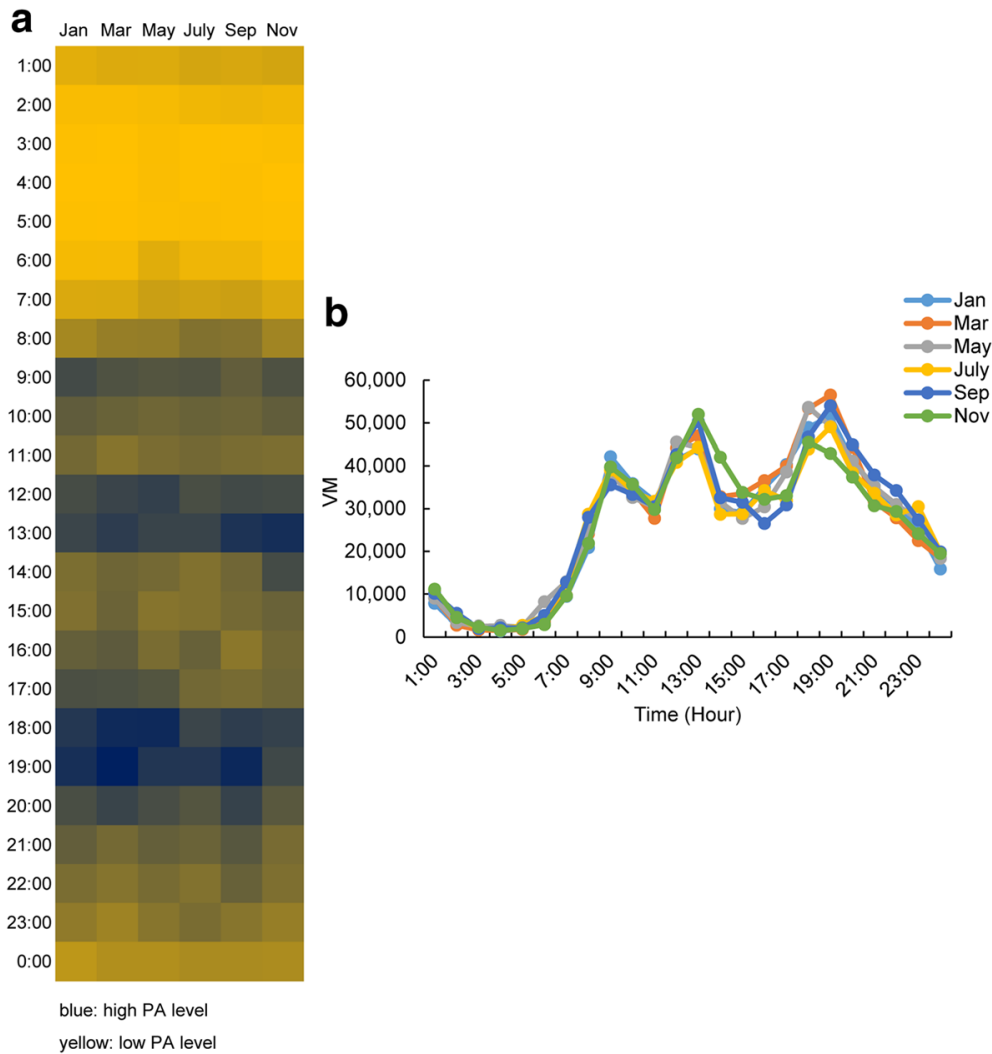

Fig. 3 Profile of 24-h total physical activity of each month. $\mathbf{a}$ is the heatmap of physical activity profile where darker blue indicates the higher PA level while the lighter yellow represents the lower level. The most active times of a day were around 9:00, 12:00-13:00, 18:00-19:00, either the time after meals or commuting between work and home. $\mathbf{b}$ represents the level of physical activity level across the $24 \mathrm{~h}$ in a day. There is no significant difference of the average physical activity across the months

general recommendation of physical activity of the world health organization.

Previous studies, across a range of age groups from children to the elderly, including studies that have used the same activity logger we used, have suggested that PA levels differ between the sexes [43, 45, 47, 48]. This was consistent with our results where we found males were more active than females. Age and body fatness have also been suggested to be important correlates of physical activity. In contrast to several previous studies that indicated activity declines in older people $[46,47,49]$ we found a positive relationship with age: older individuals in our sample were more active than the younger volunteers. It is important to note that because of the cross sectional nature of our study this does not imply that individuals in Beijing become more active as they get older, only that individuals born longer ago are currently more active. A number of previous studies [50-53] have shown a negative correlation between physical activity and body fatness. Recent studies have suggested this is likely because increasing levels of obesity suppress activity rather than the reverse $[54,55]$. Our study also showed the similar results. The EPIC-Norfolk study [56] also suggested a physically active lifestyle is associated with $40 \%$ reduction in genetic predisposition of common obesity.

Time of day was the most significant factor influencing the hourly PA levels. This was partly because of the strong diurnal pattern in activity with most people asleep and inactive between midnight and 6:00 am. Nevertheless, if we excluded the main sleeping time from the analysis, time of day still remained the strongest factor. We found that the hour with the greatest physical activity in all the months except November was 18:00 to 19:00. In November it was 17:00 to 18:00. The consistent timing of this early evening activity throughout the year was probably driven by the invariant nature of work patterns independent of season. This potentially explains why there were also no significant effects of ambient temperature and PM2.5 as individuals timed their activities according to their work days rather than responding to environmental cues. It is worth knowing that all the volunteers we recruited had occupations where they worked indoors. Patterns may be different for individuals with occupations that include significant levels of outdoor activity. Nevertheless although the 


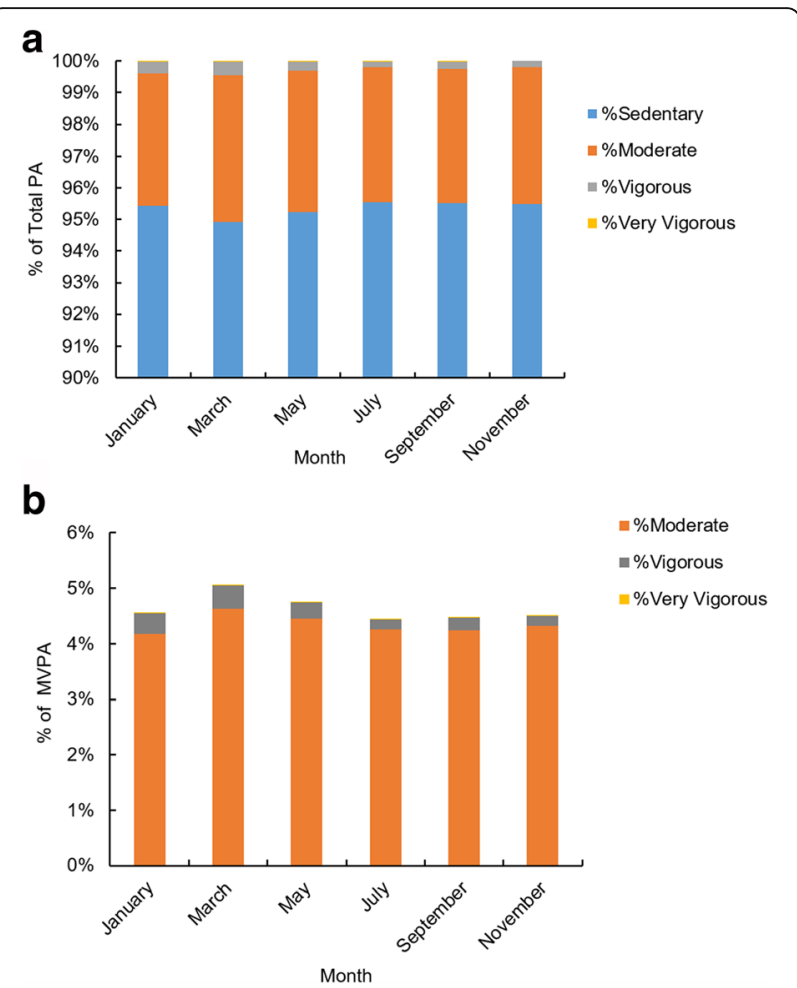

Fig. 4 Seasonal differences in the intensity of physical activity. $\mathbf{a}$ is the patterns for percentage time spent at each intensity level of physical activity in each month. The sedentary to light physical activity always occupied almost $95 \%$ of the time. The moderate to vigorous physical activity occupied around $5 \%$ of the time. There were no seasonal differences in the time spent at different intensities of physical activity. $\mathbf{b}$ shows the patterns for percentage of moderate to vigorous physical activity level

peak evening activity coincided with the likely commuting time, these individuals remained relatively active throughout the evening suggesting that also the individuals had rather invariant patterns of leisure time activity as well.

The current study indicated that a single week long measurement by the GT3x would be representative of physical activity levels of this population without serious seasonal bias. One limitation of our study is the GT3x couldn't measure the physical activity under water such as swimming and upper body movements during activities like cycling. This may underestimate the exact physical activity of our subjects, although according the life-style questionnaire with our subjects, few of them chose to go swimming. Another limitation of this longitudinal study was the relatively small sample size of subjects that completed the entire study. It was very hard to keep tracking the same people over the entire year and the dropout rate was high due to various reasons like pregnancy and changing jobs - hence moving out of the area. It would also have been useful for the subjects to have completed a more detailed activity diary during each measurement period so that we knew not only how active they had been but what they were actually doing.

\section{Conclusions}

In our study, we found that there was no seasonal variation in physical activity and no significant effects of ambient temperature and air pollution (PM2.5). People's PA level was most responsive to time of day rather than other factors, presumably because individuals followed a fairly constant behavior pattern driven by their work demands. Despite this individual characteristics including body fatness, sex and age also influenced the PA level. Older individuals and males were more active. For surveys of activity our data indicate that measurements on a single week long occasion would be sufficient to represent the physical activity level of this population.

\section{Additional file}

Additional file 1: Human subject criterion file Life-style questionnaire (in Chinese). Figure S1. Workflow of the experiment. 40 subjects were recruited at the beginning of the experiment. Basic demographic information was captured. They came to visit lab every two months to get the accelerometer GT3X fitted and measured the body composition. (DOCX 205 kb)

\section{Abbreviations}

BMl: Body mass index; CPM: Counts per minute; GLM: General linear model; MVPA: Moderate to vigorous physical activity; PA: Physical activity; PM2.5: Particulate matter with a diameter less than 2.5 microns; VM: Vector magnitude

\section{Acknowledgements}

We are also grateful for the support of all the volunteers who participated in our study. We are grateful to Beijing Urban Ecosystem Research Station provided the hourly temperature and PM 2.5 data. We are grateful to the USA CDC for the loan of some of the GT3X accelerometers used in this study.

\section{Funding}

This study was funded by National Natural Science Foundation of China (NSFC 91431102) and International Cooperation Program of Chinese Academy of Sciences (GJHZ1660). John R. Speakman was supported by the 1000 talents program of the Chinese government and a Wolfson merit award from the Royal Society.

\section{Availability of data and materials}

The datasets generated and/or analyzed during the current study are not publicly available due to confidentiality reasons, but are available from the corresponding author on reasonable request.

\section{Authors' contribution}

JRS and GLW designed and conceived the study. GLW, XYZ and BGL measured the body composition. GLW, BGL, CQN, JBL, LL and XYZ were involved in recruiting subjects and measuring demographic and anthropometric data. GLW logged the GT3X for physical activity measurements. GLW analyzed data. GLW and JRS co-wrote the manuscript. All authors read and approved the final manuscript.

\section{Competing interests}

The authors declare that they have no competing interests.

Consent for publication

Not applicable. 


\section{Ethics approval and consent to participate}

This study was approved by the Institutional Review Board (IRB) in Institute of Genetics and Developmental Biology (IGDB), Chinese Academy of Sciences (approval No. 2014-IGDB-IRB-004). All the subjects gave both oral and written informed consent during their first trip to the laboratory.

\section{Publisher's Note}

Springer Nature remains neutral with regard to jurisdictional claims in published maps and institutional affiliations.

\section{Author details}

${ }^{1}$ State Key Laboratory of Molecular Developmental Biology, Institute of Genetics and Developmental Biology, Chinese Academy of Sciences, Beijing, China. ${ }^{2}$ University of Chinese Academy of Sciences, Beijing, China. ${ }^{3}$ Department of Physiology and Pathophysiology, Basic Medical College of Dali University, Dali, Yunnan, China. ${ }^{4}$ Institute of Biological and Environmental Sciences, University of Aberdeen, Aberdeen, UK.

\section{Received: 24 January 2017 Accepted: 3 April 2017}

Published online: 17 April 2017

\section{References}

1. Organization WH. Global recommendations on physical activity for health. 2010.

2. Murray CJ, Lopez AD. Global mortality, disability, and the contribution of risk factors: global burden of disease study. Lancet. 1997;349(9063):1436-42.

3. Blair SN, Morris JN. Healthy hearts - and the universal benefits of being physically active: physical activity and health. Ann Epidemiol. 2009;19(4):253-6.

4. Gillies CL, Abrams KR, Lambert PC, Cooper NJ, Sutton AJ, Hsu RT, Khunti K. Pharmacological and lifestyle interventions to prevent or delay type 2 diabetes in people with impaired glucose tolerance: systematic review and meta-analysis. BMJ. 2007;334(7588):299.

5. Lee I-M, Shiroma E, Lobelo F, Puska P, Blair SN, Katzmarzyk PT, Group LPASW. Effect of physical inactivity on major non-communicable diseases worldwide: an analysis of burden of disease and life expectancy. Lancet. 2012;380(9838):219-29.

6. Bauman AE, Reis RS, Sallis JF, Wells JC, Loos RJ, Martin BW, Group LPASW. Correlates of physical activity: why are some people physically active and others not? Lancet. 2012;380(9838):258-71.

7. Joosen AM, Gielen M, Vlietinck R, Westerterp KR. Genetic analysis of physical activity in twins. Am J Clin Nutr. 2005;82(6):1253-9.

8. Otabe S, Clement K, Dina C, Pelloux V, Guy-Grand B, Froguel P, Vasseur F. A genetic variation in the $5^{\prime}$ flanking region of the UCP3 gene is associated with body mass index in humans in interaction with physical activity. Diabetologia. 2000;43(2):245-9.

9. Vimaleswaran KS, Li S, Zhao JH, Luan J, Bingham SA, Khaw K-T, Ekelund U, Wareham NJ, Loos RJ. Physical activity attenuates the body mass index-increasing influence of genetic variation in the FTO gene. Am J Clin Nutr. 2009;90(2):425-8.

10. Humpel N, Owen N, Leslie E. Environmental factors associated with adults' participation in physical activity: a review. Am J Prev Med. 2002;22(3):188-99.

11. Hajat $\mathrm{S}, \mathrm{O}^{\prime} \mathrm{C}$ onnor M, Kosatsky $\mathrm{T}$. Health effects of hot weather: from awareness of risk factors to effective health protection. Lancet. 2010;375(9717):856-63.

12. Speakman JR, Heidari-Bakavoli S. Type 2 diabetes, but not obesity, prevalence is positively associated with ambient temperature. Sci Rep. 2016;6:30409.

13. Stevenson T, Visser M, Arnold W, Barrett P, Biello S, Dawson A, Denlinger D, Dominoni D, Ebling F, Elton S. Disrupted seasonal biology impacts health, food security and ecosystems. In: Proc R Soc B: 2015: The Royal Society; 2015: 20151453.

14. Matthews CE, Freedson PS, Hebert JR, Stanek EJ, Merriam PA, Rosal MC, Ebbeling CB, Ockene IS. Seasonal variation in household, occupational, and leisure time physical activity: longitudinal analyses from the seasonal variation of blood cholesterol study. Am J Epidemiol. 2001;153(2):172-83.

15. Berkey CS, Rockett HR, Gillman MW, Colditz GA. One-year changes in activity and in inactivity among 10-to 15-year-old boys and girls: relationship to change in body mass index. Pediatrics. 2003;111(4):836-43.

16. Ravindra K, Sidhu MK, Mor S, John S, Pyne S: Air Pollution in India: Bridging the Gap between Science and Policy. Journal of Hazardous, Toxic, and Radioactive Waste. 2015;20(4):A4015003. http://dx.doi.org/10.1061/(ASCE)HZ. 2153-5515.0000303\#sthash.B3EbgFo2.dpuf.

17. Zheng S, Pozzer A, Cao C, Lelieveld J. Long-term (2001-2012) concentrations of fine particulate matter (PM 2.5) and the impact on human health in Beijing, China. Atmospheric Chemistry and Physics. 2015;15(10):5715-25.
18. Li F, Liu Y, Lü J, Liang L, Harmer P. Ambient air pollution in China poses a multifaceted health threat to outdoor physical activity. J Epidemiol Community Health. 2015;69(3):201-4.

19. Raaschou-Nielsen O, Andersen ZJ, Beelen R, Samoli E, Stafoggia M, Weinmayr G, Hoffmann B, Fischer P, Nieuwenhuijsen MJ, Brunekreef B. Air pollution and lung cancer incidence in 17 European cohorts: prospective analyses from the European Study of Cohorts for Air Pollution Effects (ESCAPE). Lancet Oncol. 2013;14(9):813-22.

20. Franklin M, Zeka A, Schwartz J. Association between PM2. 5 and all-cause and specific-cause mortality in 27 US communities. J Expo Sci Environ Epidemiol. 2007;17(3):279-87.

21. He K, Yang F, Ma Y, Zhang Q, Yao X, Chan CK, Cadle S, Chan T, Mulawa P. The characteristics of PM 2.5 in Beijing, China. Atmos Environ. 2001;35(29):4959-70.

22. Zheng M, Salmon LG, Schauer JJ, Zeng L, Kiang C, Zhang Y, Cass GR. Seasonal trends in PM2. 5 source contributions in Beijing, China. Atmos Environ. 2005:39(22):3967-76

23. Hagströmer M, Oja P, Sjöström M. The International Physical Activity Questionnaire (IPAQ): a study of concurrent and construct validity. Public Health Nutr. 2006;9(06):755-62.

24. Bull FC, Maslin TS, Armstrong T. Global physical activity questionnaire (GPAQ): nine country reliability and validity study. J Phys Act Health. 2009;6(6):790.

25. Washburn RA, Smith KW, Jette AM, Janney CA. The Physical Activity Scale for the Elderly (PASE): development and evaluation. J Clin Epidemiol. 1993; 46(2):153-62.

26. Speakman J. Doubly labelled water: theory and practice: Springer Science \& Business Media. 1997.

27. Schneider PL, Crouter SE, Bassett DR. Pedometer measures of free-living physical activity: comparison of 13 models. Med Sci Sports Exerc. 2004;36(2): $331-5$.

28. Freedson PS, Miller K. Objective monitoring of physical activity using motion sensors and heart rate. Res Q Exerc Sport. 2000;71(Sup 2):21-9.

29. Ward DS, Evenson KR, Vaughn A, Rodgers AB, Troiano RP. Accelerometer use in physical activity: best practices and research recommendations. Med Sci Sports Exerc. 2005;37(11 Suppl):S582-88.

30. Bouten CV, Koekkoek KT, Verduin M, Kodde R, Janssen JD. A triaxial accelerometer and portable data processing unit for the assessment of daily physical activity. IEEE Trans Biomed Eng. 1997;44(3):136-47.

31. Santos-Lozano A, Marín PJ, Torres-Luque G, Ruiz JR, Lucía A, Garatachea N. Technical variability of the GT3X accelerometer. Med Eng Phys. 2012;34(6):787-90.

32. Mathie MJ, Coster AC, Lovell NH, Celler BG. Accelerometry: providing an integrated, practical method for long-term, ambulatory monitoring of human movement. Physiol Meas. 2004;25(2):R1.

33. Uitenbroek DG. Seasonal variation in leisure time physical activity. Med Sci Sports Exerc. 1993;25(6)755-60.

34. Hamilton SL, Clemes SA, Griffiths PL. UK adults exhibit higher step counts in summer compared to winter months. Ann Hum Biol. 2008; 35(2):154-69.

35. Clemes SA, Hamilton SL, Griffiths PL. Summer to winter variability in the step counts of normal weight and overweight adults living in the UK. J Phys Act Health. 2011;8(1):36-44.

36. O'Connell SE, Griffiths PL, Clemes SA. Seasonal variation in physical activity, sedentary behaviour and sleep in a sample of UK adults. Ann Hum Biol. 2014:41(1):1-8.

37. Tudor-Locke C, Bassett DR, Swartz AM, Strath SJ, Parr BB, Reis JP, DuBose KD, Ainsworth BE. A preliminary study of one year of pedometer selfmonitoring. Ann Behav Med. 2004;28(3):158-62.

38. Plasqui $G$, Westerterp KR. Seasonal variation in total energy expenditure and physical activity in Dutch young adults. Obes Res. 2004;12(4):688-94.

39. McCormack GR, Friedenreich C, Shiell A, Giles-Corti B, Doyle-Baker PK. Sex-and age-specific seasonal variations in physical activity among adults. J Epidemiol Community Health. 2010;64(11):1010-6.

40. Hjorth MF, Chaput J-P, Michaelsen K, Astrup A, Tetens I, Sjödin A. Seasona variation in objectively measured physical activity, sedentary time, cardiorespiratory fitness and sleep duration among 8-11 year-old Danish children: a repeated-measures study. BMC Public Health. 2013;13(1):808.

41. Rich C, Griffiths $\amalg$, Dezateux C. Seasonal variation in accelerometerdetermined sedentary behaviour and physical activity in children: a review. Int J Behav Nutr Phys Act. 2012;9(1):49.

42. Kolle E, Steene-Johannessen J, Andersen LB, Anderssen SA. Seasonal variation in objectively assessed physical activity among children and adolescents in Norway: a cross-sectional study. Int J Behav Nutr Phys Act. 2009;6(1):1. 
43. Ridgers ND, Salmon J, Timperio A. Too hot to move? Objectively assessed seasonal changes in Australian children's physical activity. Int J Behav Nutr Phys Act. 2015;12(1):77.

44. Sasaki JE, John D, Freedson PS. Validation and comparison of ActiGraph activity monitors. J Sci Med Sport. 2011;14(5):411-6.

45. Arnardottir NY, Koster A, Van Domelen DR, Brychta RJ, Caserotti P, Eiriksdottir G, Sverrisdottir JE, Launer L, Gudnason V, Johannsson E. Objective measurements of daily physical activity patterns and sedentary behaviour in older adults: Age, Gene/Environment Susceptibility-Reykjavik Study. Age Ageing. 2013;42(2):222-9.

46. Caspersen CJ, Pereira MA, Curran KM. Changes in physical activity patterns in the United States, by sex and cross-sectional age. Med Sci Sports Exerc. 2000;32(9):1601-9.

47. Speakman JR, Westerterp KR. Associations between energy demands, physical activity, and body composition in adult humans between 18 and 96 y of age. Am J Clin Nutr. 2010;92(4):826-34.

48. Soini A, Tammelin T, Sääkslahti A, Watt A, Villberg J, Kettunen T, Mehtälä A, Poskiparta M. Seasonal and daily variation in physical activity among threeyear-old Finnish preschool children. Early Child Dev Care. 2014;184(4):589-601.

49. Hallal PC, Andersen LB, Bull FC, Guthold R, Haskell W, Ekelund U, Group LPASW. Global physical activity levels: surveillance progress, pitfalls, and prospects. Lancet. 2012;380(9838):247-57.

50. Klesges RC, Klesges L, Haddock CK, Eck LH. A longitudinal analysis of the impact of dietary intake and physical activity on weight change in adults. Am J Clin Nutr. 1992;55(4):818-22.

51. Haapanen N, Milunpalo S, Pasanen M, Oja P, Vuori I. Association between leisure time physical activity and 10-year body mass change among workingaged men and women. Int J Obes Relat Metab Disord. 1997;21(4):288-96.

52. Ekelund U, Yngve A, Brage S, Westerterp K, Sjöström M. Body movement and physical activity energy expenditure in children and adolescents: how to adjust for differences in body size and age. Am J Clin Nutr. 2004;79(5):851-6.

53. Ness AR, Leary SD, Mattocks C, Blair SN, Reilly JJ, Wells J, Ingle S, Tilling K, Smith GD, Riddoch C. Objectively measured physical activity and fat mass in a large cohort of children. PLoS Med. 2007;4(3):e97.

54. Petersen L, Schnohr P, Sørensen T. Longitudinal study of the long-term relation between physical activity and obesity in adults. Int J Obes. 2004; 28(1):105-12.

55. Metcalf BS, Hosking J, Jeffery A, Voss L, Henley W, Wilkin T. Fatness leads to inactivity, but inactivity does not lead to fatness: a longitudinal study in children (EarlyBird 45). Arch Dis Child. 2010;7(8):archdischild175927.

56. Li S, Zhao JH, Luan J, Ekelund U, Luben RN, Khaw K-T, Wareham NJ, Loos RJ. Physical activity attenuates the genetic predisposition to obesity in 20,000 men and women from EPIC-Norfolk prospective population study. PLoS Med. 2010;7(8):e1000332

\section{Submit your next manuscript to BioMed Central} and we will help you at every step:

- We accept pre-submission inquiries

- Our selector tool helps you to find the most relevant journal

- We provide round the clock customer support

- Convenient online submission

- Thorough peer review

- Inclusion in PubMed and all major indexing services

- Maximum visibility for your research

Submit your manuscript at www.biomedcentral.com/submit

\section{( ) Biomed Central}

